\title{
Resource Use Efficiency of Tea Production in Vietnam: Using Translog SFA Model
}

\author{
Nguyen Bich Hong ${ }^{1,2}$ \& Mitsuyasu Yabe ${ }^{1}$ \\ ${ }^{1}$ Environmental Economics Laboratory, Department of Agriculture and Resource Economics, Faculty of \\ Agriculture, Graduate School of Bioresource and Bioenvironmental Sciences, Kyushu University, Fukuoka City, \\ Japan \\ ${ }^{2}$ Thai Nguyen University of Economics \& Business and Administration, Thai Nguyen, Vietnam \\ Correspondence: Nguyen Bich Hong, Environmental Economics Laboratory, Department of Agriculture and \\ Resource Economics, Faculty of Agriculture, Graduate School of Bioresource and Bioenvironmental Sciences, \\ Kyushu University, 6-10-1, Hakozaki, Higashi-Ku, Fukuoka City, Japan. Tel: 81-092-642-2960. E-mail: \\ nguyen.bich.hong85@gmail.com
}

Received: June 24, 2015 Accepted: July 15, 2015 Online Published: August 15, 2015

doi:10.5539/jas.v7n9p160 URL: http://dx.doi.org/10.5539/jas.v7n9p160

\begin{abstract}
As one of the most important economic activities to small households of Vietnam, tea production is hindered by low productivity, rising of production costs, and bad agriculture practices. To sustain tea production, the near-term strategy is to improve the efficiency of resource utilization. To our knowledge, this article is the first study to evaluate the tea production's resource use efficiency and to identify the factors affecting it in Vietnam. The data was collected from 243 randomly selected tea farmers in the Northern mountainous region of Vietnam. The study first applied a translog stochastic production frontier model and technical efficiency (TE) technique to estimate resources use efficiency, and then used a Tobit model to identify the factors affecting these efficiencies among tea farms. Based on the mean sum of output elasticity with respect to inputs $(0.323)$, we found that increasing the utilization of resources in the study site was inappropriate. The study also revealed that the average input-oriented TE of tea farms was lower than that of output-oriented TE, $82.21 \%$ versus $92.29 \%$, suggesting that the farmers had more ability to reduce resource use than to increase current output level. The results showed that the tea farmers could use resources more efficiently by reducing $17.79 \%$ of the current application level without compromising the output. The study also indicates that concerted efforts from government to increase farmers' accessing extension service, widening soil and water conservation practice, and spreading farmers' awareness on water scarcity is the key to improve farmers' resource use efficiency.
\end{abstract}

Keywords: resource use efficiency, stochastic frontier analysis, tea production, Vietnam

\section{Introduction}

Tea is the second most popular and cheapest beverage next to water. It is an important commodity in terms of jobs and export earnings for a number of developing countries. In Vietnam, tea has been cultivated and drunk there for thousands of years. Today, Vietnam is the fifth largest tea exporter in the world. Tea is grown in 36 of 64 Vietnamese provinces (GSO, 2013). The best quality products are achieved in the Northern mountainous area. Tea production is an important source of national income. A total of 146,700 tons was exported and grossed 224.6 million dollars in 2012 (Vietnamese Tea Association, 2012). As a labor intensive industry, the tea sector provides employment all-year-round to about 400,000 small households in the rural areas and creates over 1.5 million jobs in other parts of the tea value chain (GSO, 2011).

Despite its importance, Vietnamese tea sector is faced with a number of constraints affecting tea production's productivity, tea farmers' livelihood and environment. The tea industry in Vietnam is performing below its potential: yields and productivity are low (Asian Development Bank, 2004). In a review of six major tea producing countries (India, Indonesia, Sri Lanka, Kenya, Vietnam and Malawi), Van der Wal (2008) showed that Vietnamese tea production is hindered by rising production costs (labor, fuel and electricity), bad agricultural practices, low labor productivity, and dilapidated infrastructure.

Addressing the emerging issues requires adoption of technologies and practices that are easily accessible to and 
effective for tea farmers, can lead to improvements in tea productivity and have positive side-effects on environment. In Vietnam, considerable work is being done to expand new technologies application in tea production. However, the implementation of these practices is lagging (Wenner, 2011). The problem is that tea production is dominated by small-scale rural farms. Most of rural farmers are not exposed to these new technologies and do not have access to basic resource. In cases where they have been exposed to it, financial constraints will not afford them the opportunity to use the technology. Hence, most tea farmers still depend on their conventional methods for farming. Furthermore, when farmers cultivate their crops with the existing technology inefficiently, applying new technologies is less cost-effective than using the existing technology (Belbase \& Grabowki, 1985; Shapiro, 1977). As such Vietnamese tea productivity should be increased by using the existing resources efficiently.

Resource use efficiency in agricultural production has been an important subject of empirical investigation in developing countries, where majority of the farmers are resource-poor. Through efficient use of resources, productivity of agricultural production can be expanded and sustained by farmers. Agricultural production is the process of transforming inputs such as seed, fertilizer, pesticide, water, labor, capital and other inputs in to goods and services called output. These resources can be organized in a farm whose ultimate objectives are output maximization, cost minimization, and profit maximization. In this production process, the farmer should be concerned with efficiency in the use of resources to achieve his objectives. Efficiency estimation will provide us useful information about the manner in which farms should utilize inputs to produce goods and services. One of types of efficiency which is popularly identified in literature is technical efficiency. Technical efficiency (TE) is measured as the ratio between the observed output to the maximum output, under the assumption of fixed inputs (output orientation), or, alternatively, as the ratio between the minimum input to the observed input, under the assumption of fixed outputs (input orientation) (Farell, 1957; Coelli et al., 2005).

There are two methods widely used in the literature to estimate technical efficiency. First, Stochastic Frontier Analysis (SFA) is an econometric approach that was simultaneously introduced by Aigner, Lovell and Schmidt (1977) and Meeusen and Van den Broeck (1977). Second, Data Envelopment Analysis (DEA) is non-parametric approach or mathematical programming. Two methods have partial strength and weakness. The econometric method is stochastic and parametric. It distinguishes the effects of noise with the effects of inefficiency and confounds the effect of misspecification of functional form with inefficiency. It generates good results for models with single output and multiple inputs. Conversely, the mathematical programming approach is not stochastic and not parametric. It cannot separate the effects of noise and the effects of inefficiency during the calculation of technical efficiency, and it less sensitive to the type of specification error (Kebede, 2001). Its advantage is that multiple inputs and output can be considered simultaneously, and inputs and outputs can be quantified using different units of measurement. Since tea production is mono crop farming and frequently affected by weather conditions, diseases, and other exogenous random factors (noise effects), stochastic frontier analysis was applied for this study to distinguish noise effects and inefficiency effects in the model.

In recent years, there have been some studies on tea production efficiency estimation in developing countries (Basnayake \& Gunaratne, 2000; Baten et al., 2010; Haridas et al., 2012), particularly in Vietnam such as Saigenji and Zeller (2009). By using stochastic frontier analysis, all these studies showed clearly output-oriented technical efficiency of tea production which determined tea farms' possibility to maximize output levels with given set of inputs, but their limitation were not to estimate the input-oriented technical efficiency. The input-oriented technical efficiency is defined as the feasible of minimum to observed level of inputs, conditional on observed levels of outputs (Coelli et al., 2005; Reinhard et al., 1999). The present study hopefully would fill this gap. The objectives of the study are to estimate resource use efficiency and to identify the determinants of tea production Vietnam using stochastic frontier approach and technical efficiency technique. Based on technical details, the study will provide useful information on the method in which farms should utilize resources efficiently to produce tea in the research site.

The paper is organized as follows. The next section presents methodology and the data collection procedure. This section explains the concepts of technical efficiency, models the output-input oriented technical efficiency of tea farms, as well as factors affecting them. Results and discussion are presented in the third section. Conclusions and implications are formulated in section 4 .

\section{Methodology and Data Collection}

\subsection{Methodology}

Technical efficiency (TE) is measured as the ratio between the observed output to the maximum output, under the assumption of fixed inputs, or, alternatively, as the ratio between the minimum input to the observed input, 
under the assumption of fixed outputs (Farell, 1957; Coelli et al., 2005). Two models of TE are primarily used in the efficiency literature. These are: (i) input-oriented (IO) technical efficiency, (ii) output-oriented (OO) technical efficiency. There are some basic differences between the IO and OO models so far as features of the technology are concerned. The models of technical efficiency graphically in case of a single input and a single output is described in Figure 1.

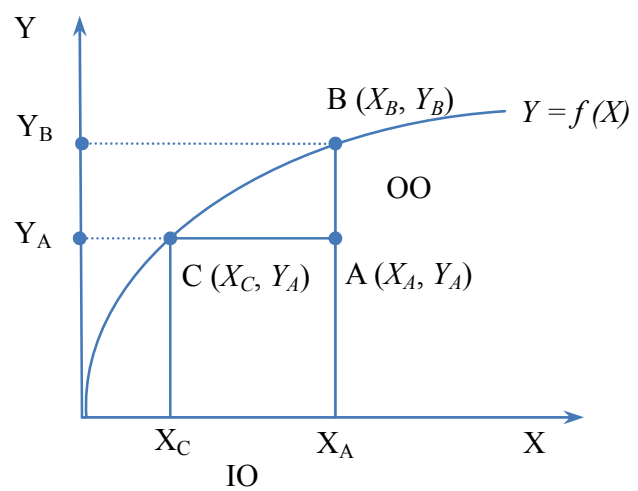

Figure 1. Technical efficiency concepts in the production frontier framework

The curve $\mathrm{CB}$ represents the frontier: any economy can lie either on the curve (i.e. points $\mathrm{B}$ and $\mathrm{C}$ ) or below the curve (i.e. point A). Staying below the frontier point $\mathrm{A}$ is inefficient because it could either increase output from $Y_{A}$ to $Y_{B}$ without consuming any extra input or reduce input consumption from $X_{A}$ to $X_{C}$ without compromising output. A distance from point $\mathrm{A}$ to either point $\mathrm{B}$ or $\mathrm{C}$ represents its inefficiency levels. There are two general ways to achieve efficiency improvements: moving from point A to point B (i.e. output-oriented framework) or moving from point $\mathrm{A}$ to point $\mathrm{C}$ (i.e. input-oriented framework).

Aigner et al. (1977) and Meeusen and Van den Broeck (1977) developed the stochastic frontier analysis (SFA) to estimate output - oriented TE of firms/producers using parametric econometric techniques. Reinhard et al. (1999) followed the approach of Aigner et al. (1977) and Meeusen and Van den Broeck (1977), and then extended their approach to estimate environmental efficiency (EE) which measures the potential reduction of environmentally detrimental inputs. The authors also considered input-oriented technical efficiency by applying the similar manner of environmental efficiency measurement. Along the line of Aigner et al. (1977), Meeusen and Van den Broeck (1977), and Reinhard et al. (1999), this paper estimates resource use efficiency of tea production based on both output-oriented TE and input-oriented TE evaluation.

We assume that a tea farm produces a vector of single output denoted as $Y$, with $Y \in R_{+}^{M}$ by using inputs $X$ $\left(X \in R_{+}^{N}\right.$ ). The stochastic production frontier function of the $i$-th tea farm is defined as following:

$$
Y_{i}=f\left(X_{i}, \alpha\right) \exp \left(\varepsilon_{i}\right)
$$

Where, all farms are indexed with a subscript $i ; Y_{i}$ denotes the fresh tea yield level; $X_{i}$ is a vector of inputs (with $X_{i 1}$ is the fertilizer, $X_{i 2}$ is the pesticide, $X_{i 3}$ is the capital, $X_{i 4}$ is the irrigation water, $X_{i 5}$ is the labor, $X_{i 6}$ is the other cost); $\alpha$ is parameters to be estimated; $\varepsilon_{i}$ is the composed error term, which is equal to $v_{i}-u_{i}$. The term $v_{i}$ is a two-sided $\left(-\infty<v_{i}<\infty\right)$ normally distributed random error $\left(v \sim N\left[0, \sigma_{v}^{2}\right]\right)$ that represents the stochastic effects outside the farmer's control (e.g., weather; natural disasters, and luck), measurement errors, and other statistical noise. The term $u_{i}$ is nonnegative random error term, independently and identically distributed as $N^{+}\left(0, \sigma_{u}^{2}\right)$ that represents the technical inefficiency of farm (Coelli et al., 2005).

Equation (1) estimated by the maximum likelihood analysis creates consistent estimators for $\alpha, \lambda$, and $\sigma$. Where $\lambda=\sigma_{u} / \sigma_{v}, \sigma^{2}=\sigma_{u}^{2}+\sigma_{v}^{2}$.

According to Battese and Corra (1977), the ratio variance parameter $\gamma$ which relates to the variability of $u_{i}$ to total variability $\sigma^{2}$ can calculate in the following manner:

$$
\gamma=\sigma_{u}^{2} / \sigma^{2}
$$

$$
\text { So that } 0 \leq \gamma \leq 1
$$

If the value of $\gamma$ is equal to zero, the difference between actual farmer yield and the efficient yield is entirely due to statistical noise. On the other hand, a value of one would indicate the difference attributed to the farmers' less 
than efficient use of technology i.e. technical inefficiency (Coelli et al., 2005).

The technical inefficiency of individual farm can be estimated by using conditional distribution of $u_{i}$ given the fitted values of $\varepsilon_{i}$ and respective parameters (Jondrow et al., 1982). If we assume that $v_{i}$ and $u_{i}$ are independent of each other, the conditional mean of $u_{i}$ given $\varepsilon_{i}$ is identified by:

$$
\mathrm{E}\left(u_{i} \mid \varepsilon_{i}\right)=\sigma^{*}\left[\frac{f^{*}\left(\varepsilon_{i} \lambda / \sigma\right)}{1-F^{*}\left(\varepsilon_{i} \lambda / \sigma\right)}-\frac{\varepsilon_{i} \lambda}{\sigma}\right]
$$

Where, $\sigma^{* 2}=\sigma_{u}{ }^{2} \sigma_{v}{ }^{2} / \sigma^{2}, f^{*}$ is the standard normal density function, and $F^{*}$ is the distribution function, both functions being estimated at $\varepsilon \lambda / \sigma$.

The output-oriented technical efficiency of the $i$-th tea farm is determined by the follow function:

$$
T E_{i}=\frac{y_{i}}{f\left(X_{i}, \alpha\right) \exp \left(v_{i}\right)}=\exp \left(-E\left(u_{i} \mid \varepsilon_{i}\right)\right)=\exp \left(-\hat{u}_{i}\right)
$$

Where, $y_{i}$ is the observed fresh tea yield level of the $i$-th tea farm, $f\left(X_{i}, \alpha\right) \exp \left(v_{i}\right)$ is the maximum feasible of tea yield adjusted for statistical noise. $T E_{i}$ score is between 0 and 1 . A farm is fully efficient if $T E$ equals to 1 and fully inefficient if its value is 0 .

With the assumption of half-normal model, a simple z-test will be used for examining the existence of technical inefficiency, the null and alternative hypotheses are: $\mathrm{H}_{0}: \lambda=0$ (Coelli et al., 2005). The test statistic is:

$$
z=\frac{\tilde{\lambda}}{\operatorname{se}(\tilde{\lambda})} \sim N(0,1)
$$

Where: $\tilde{\lambda}$ is the maximum likelihood estimator of $\lambda$ and $\operatorname{se}(\tilde{\lambda})$ is the estimator for its standard error.

To obtain a stochastic model of the input-oriented technical efficiency measure, a stochastic production frontier function needs to be specified. In this study, we used a flexible translog functional form to avoid excessive misspecification and ensure input-oriented TE measure based on random output elasticities and inefficiency effect (Reinhard et al., 1999). Equation (1) is written in translog form as follows:

$$
\ln Y_{i}=\alpha_{0}+\sum_{j} \alpha_{j} \ln X_{i j}+\frac{1}{2} \sum_{j} \sum_{k} \alpha_{j k} \ln X_{i j} \ln X_{i k}+v_{i}-u_{i}
$$

Where: $\ln Y_{i}$ represents for the natural logarithm of tea yield of the $i$-th tea farm, $j=1 \ldots 6, k=1 \ldots 6, \alpha_{j k}=\alpha_{k j}$.

The logarithm of tea yield of an output-oriented technically efficient farmer apart from the statistical noise captured by the error term $v_{i}$ is obtained by setting $u_{i}=0$ in (6). The logarithm of tea yield of an input-oriented technically efficient farmer apart from the statistical noise is obtained by replacing $X_{i}$ with $X_{i F}=\delta_{i} X_{i}$ and setting $u_{i}=0$ in (6), where $X_{i F}$ is minimum input, $\delta_{i}$ is input-oriented $T E$. The input-oriented specification is given by:

$$
\ln Y_{i}=\alpha_{0}+\sum_{j} \alpha_{j} \ln \left(\delta_{i} X_{i j}\right)+\frac{1}{2} \sum_{j} \sum_{k} \alpha_{j k} \ln \left(\delta_{i} X_{i j}\right) \ln \left(\delta_{i} X_{i k}\right)+v_{i}
$$

Setting the output-oriented specification in Equation (6) equal to the input-oriented specification in Equation (7) permits the isolation of the logarithms of the stochastic input-oriented TE measure:

$$
\sum_{j} \alpha_{j} \ln \delta_{i}+\frac{1}{2} \sum_{j} \sum_{k} \alpha_{j k}\left[\left(\ln \delta_{i}\right)^{2}+\ln \delta_{i}\left(\ln X_{i j}+\ln X_{i k}\right)\right]+u_{i}=0
$$

Resulting in

Where, $b_{i}=\Sigma_{j} \alpha_{j}+\frac{1}{2} \Sigma_{j} \Sigma_{k} \alpha_{j k}\left(\ln X_{i j}+\ln X_{i k}\right)$.

$$
\frac{1}{2} \sum_{j} \sum_{k} \alpha_{j k}\left(\ln \delta_{i}\right)^{2}+b_{i}\left(\ln \delta_{i}\right)+u_{i}=0
$$

Application for the quadratic equation formula (9) gives the solution for the variable $\ln \delta_{i}$ :

$$
\ln \delta_{i}=\frac{-b_{i} \pm \sqrt{b_{i}^{2}-2 u_{i} \Sigma_{j} \Sigma_{k} \alpha_{j k}}}{\Sigma_{j} \Sigma_{k} \alpha_{j k}}
$$

According to Reinhard et al. (1999), a farm which is technically efficient from output-oriented perspective $\left[u_{i}=\right.$ 0 in Equation (6)] must also be technically efficient from an input-oriented perspective $\left[\delta_{i}=1\right.$ in Equation (7)].

Thus, input-oriented $T E$ in Equation (9) is measured by using positive sign as follows:

$$
\delta_{i}=\exp \left(\frac{-b_{i}+\sqrt{b_{i}^{2}-2 u_{i} \Sigma_{j} \Sigma_{k} \alpha_{j k}}}{\Sigma_{j} \Sigma_{k} \alpha_{j k}}\right)
$$


It is very essential to note that output elasticity with respect to specific inputs in case of translog form is different from those of Cobb-Douglass form. The output elasticity expression in translog function is presented as following:

$$
\frac{\partial \ln Y}{\partial \ln X_{j}}=\alpha_{j}+\sum_{1}^{k} \alpha_{j k} \ln X_{k}
$$

For making implications, it is very important to determine factors affecting technical efficiency. To investigate the relationship between farms' technical efficiency and various farmers' socio-economic factors and specific farm characteristics, a two-limit Tobit regression model was applied in this study because the technical efficiency scores from stochastic frontier analysis are limited between 0 and 1 (Bravo-Ureta \& Pinheriro, 1997). A Tobit regression model can be specified in the following form:

$$
T E_{i}=\omega_{0}+\sum_{i} w_{i} K_{i}+e_{i}
$$

Where, $T E_{i}$ is technical efficiency of the $i$-th tea farm, $K_{i}$ is the variables representing socio-economic characteristics of farmers and tea farms to explain technical efficiency: Age (the age of household head (years) $(k$ $=1$ ), Gender (gender of household head $(1=$ male, $0=$ female) $(k=2)$, Education (the number of completed years of schooling of household head) $(k=3)$, Household size (the number of family members in persons) $(k=$ 4), Ethnicity (ethnicity of household head ( $1=$ Kinh ethnicity, $0=$ Otherwise) $(k=5)$, Experience (the number of tea growing years) $(k=6)$, Tea age ( the age of tea tree in years) $(k=7)$, Soil and water conservation (SWC) $(1=$ if farmers applied SWC technology on their fields such as: barrier to water movement, soil bund, stone bund, contour ridge, hedge grow, planting tree, grass trip, and digging hole to store rainwater, $0=$ if farmer did not apply) $(k=8)$, Farm value in natural $\log$ (the total value of agricultural products gained by farmers) $(k=9)$, Non-agri. Income share (proportion of total farmer's income to non-agricultural sources) $(k=10)$, Extension $(1=$ access to extension service, $0=$ otherwise) $(k=11)$, Cooperative $(1=$ if farmer joining in cooperative, $0=$ otherwise) $(k=12)$; Farm size (ha) $(k=13)$, Water scarcity perception $(1=$ farmers who recognize water scarcity in the study site, $0=$ farmers who did not recognize $)(k=14)$, Well water $(1=$ well water, $0=$ otherwise $)(k=15)$, Stream water $(1=$ stream water, $0=$ otherwise $)(k=16)$.

\subsection{Data Collection}

The data used for this study were collected in Thai Nguyen province of Vietnam in 2014. Thai Nguyen is the second largest tea-planting and tea-producing province in Vietnam with 17,300 ha of tea trees and producing about 184,400 tons per year. The province also first ranks in planting and producing tea in the Northern mountainous region (GSO, 2013). The suitable natural conditions and temperate climate make Thai Nguyen tea have the finest quality throughout Vietnam. Four representative communes of two famous tea-producing districts (Dong Hy district and Thai Nguyen city) in Thai Nguyen province were chosen for the survey. The selected tea farms are representative of topographical conditions in tea production areas of Thai Nguyen province.

Trained enumerators conducted face-to-face interview with tea farmers from January to December 2014. A pre-test was made to revise the questionnaire before the formal survey. The questionnaire in this study was structured to get responses from the selected tea farmers. Farmers were trained to record their farming activities in a diary to collect information on output, inputs and cost used for tea production, especially irrigation water levels. A total of 280 tea growers were selected following a random sampling procedure. After checking data, 37 respondents were excluded from the analysis because they did not record their farming activities carefully. Finally, the sample used for estimation consisted of 243 households.

Table 1 presents the descriptive statistics of the socio-demographic and tea production characteristics of the sample.

The results showed that the average tea yield was 14,319.76 kilograms (S.D. $=1,340.90$ kilograms) and range from 10,028.64 kilograms to 17,740.02 kilograms. The large variability in standard deviation revealed that the sample farmers used inputs in different ways, which tended to affect their yield levels. Fertilizer is an important input to increase the productivity of tea. The mean fertilizer level per farm was 1,069.74 kilograms. There was a high variation in the amount of fertilizer application per farm with the range from 506.17 kilograms to $1,768.52$ kilograms. The average use of pesticide is approximately 120.82 liters per hectare, with a range from 62.95 liter to 200 liters, representing a large variability among farms. This variability may depend on farm size and farmers' attitude and preference regarding the application of pesticide. The average utilization of human labor per hectare including hired and family labors was 398.05 man-days and range from 169.75 man-days to 976.86 man-days, indicating that farming activities are highly labor intensive. The range of irrigation water per hectare was from $429.98 \mathrm{~m}^{3}$ to $3,018.21 \mathrm{~m}^{3}$, with a mean of $1,580.46 \mathrm{~m}^{3}$, suggesting a wide range variation among farms. 
Table 1. Description of variables

\begin{tabular}{lllll}
\hline Descriptive of variables & Mean & Std. Dev & Min & Max \\
\hline Tea production characteristics & & & & \\
Fresh tea yield $(\mathrm{kg} / \mathrm{ha})(Y)$ & $14,319.76$ & $1,340.90$ & $10,028.64$ & $17,740.02$ \\
Fertilizer $(\mathrm{kg} / \mathrm{ha})\left(X_{1}\right)$ & $1,069.74$ & 226.21 & 506.17 & $1,768.52$ \\
Pesticide (liter/ha) $\left(X_{2}\right)$ & 120.82 & 23.30 & 62.95 & 200.00 \\
Labor (man-day/ha) $\left(X_{3}\right)$ & 398.05 & 132.11 & 169.75 & 976.86 \\
Irrigation water (m $\left.{ }^{3} / \mathrm{ha}\right)\left(X_{4}\right)$ & $1,580.46$ & 556.11 & 429.98 & $3,018.21$ \\
Other cost (thousand VND/ha) $\left(X_{5}\right)$ & $5,072.08$ & 708.89 & $3,395.06$ & $6,983.02$ \\
Capital (thousand VND/ha) $\left(X_{6}\right)$ & $2,384.98$ & $2,238.39$ & 164.99 & $17,045.00$ \\
Household head characteristics & & & & \\
Age (years) & 45.02 & 9.42 & 21.00 & 70.00 \\
Education (years) & 10.10 & 2.16 & 5.00 & 16.00 \\
Experience (years) & 19.74 & 9.38 & 5.00 & 50.00 \\
Tea farm characteristics & & & & \\
Farm size (ha) & 0.26 & 0.14 & 0.05 & 0.60 \\
Tea age (years) & 14.86 & 7.72 & 3.00 & 36.00 \\
Farm value (million VND/ha) & 675.81 & 415.35 & 130.65 & $2,574,20$ \\
Non-agricultural income share & 0.08 & 0.13 & 0.00 & 0.59 \\
\hline
\end{tabular}

Note. a man-day unit $=8$ working hours of an adult.

Source: Author's estimation.

The average education level is around 10 years, suggesting that most of tea farmers graduated secondary school in Vietnamese education system. The results also show that farmers have longer experience on tea cultivation with the mean about 20 years. The average production area is around 0.26 ha and a range from 0.05 ha to 0.59 ha, suggesting the big variability of sizes among tea farmers in Vietnam. The results reveal that tea farmers in the Northern mountainous region of Vietnam have basic education level and longer experience in tea production, but mostly engaged in small-scale tea farming. The mean age of tea plant in the sample is quite young (around 15 years). According to Do and Le (2000), the most productive period of the tea age's life is from 10 to 30 years old. The tea age in the sample had stands ranging from 3-36 years old suggesting that most survey tea farms are in the most productive period. Farmers earned an average of 675.81 million VND per hectare from tea farming. They also earned an off-farm income at $0.08 \%$ of the total household income. This result suggests that tea production brings major income for farmers in the region.

STATA software version 11 was used to estimate stochastic production frontier and calculate both outputoriented and input-oriented TE.

\section{Results and Discussion}

\subsection{Resource Use Efficiency}

Prior to estimate stochastic production frontier, in order to define specification form and significant explanatory variables of model, we regressed translog and Cobb-Douglass (CD) stochastic frontier function with six explanatory variables (Table 1). The results from CD production frontier function form showed that five variables such as Fertilizer, Pesticide, Labor, Irrigation water, and Capital are significant at 5\% level, while the remaining variable Other cost is not significant. For this reason, Other cost variable was removed from the estimation of stochastic production frontier. We then tested the translog function with the CD function of five significant independent variables using likelihood ratio (LR) test. The null hypothesis is the restricted model or $\mathrm{CD}$ function used. The test results indicate that $\mathrm{LR}=50.07>\chi_{(15,0.5 \%)}^{2}=31.31$, which means that we rejected the null hypothesis. We therefore decided to use translog function in stochastic production frontier analysis. Besides, multicollinearity and heteroskedasticity are also two big problems causing biased for estimation of production frontier. The results from Variance Inflation Factor (VIF) and Breusch-Pagan/Cook-Weisberg test showed that neither multicollinearity (mean value of VIF $=1.27$ ) nor heteroskedasticity (probability of chi-square statistic is 
0.81 , accepting the null hypothesis of constant variance) was found in the model.

The parameter estimates of translog frontier are presented in Appendix A. This model is used to generate the output-oriented TE and the parameters estimates required to calculate input-oriented $T E$.

Before estimating technical efficiency, we considered return to scale of the existing technology in tea production. Table 2 describes the output elasticity with respect to each input. Elasticity of tea production's output with respect to each input is calculated by Equation (12). The results from Table 2 show that the sum of mean elasticities of output with respect to the five inputs $(0.323)$ is less than 1 , which suggests the presence of decreasing returns to scale in tea production in the study site. This means that equiproportional increase all inputs in tea production leads to a less than proportionate increase in output.

Table 2. Elasticity of output with respect to specific inputs

\begin{tabular}{lccll}
\hline Inputs & Mean & Lower quartile & Median & Upper quartile \\
\hline Fertilizer & 0.045 & -0.107 & 0.011 & 0.189 \\
Pesticide & 0.123 & 0.088 & 0.124 & 0.152 \\
Labor & 0.068 & 0.017 & 0.062 & 0.122 \\
Irrigation water & 0.075 & 0.048 & 0.075 & 0.108 \\
Capital & 0.012 & -0.014 & 0.011 & 0.040 \\
Total & 0.323 & 0.032 & 0.283 & 0.611 \\
\hline
\end{tabular}

Source: Author's estimation.

All the mean output elasticities with respect to each input are positive, implying that the increasing these inputs can increase the output. However, the lower quartile of output elasticities with respect to fertilizer and capital are negative, which shows that there has been over utilization of such inputs in some tea farms. Several factors may contribute to this overall pattern. Interviews with tea farmers indicated that they consider chemical fertilizer to be essential tool in increasing tea yield. They believe that the more they apply chemical fertilizer, the more output will be. Besides, to attract the customers and motivate them to pay a higher price, tea farmers use nitrogen fertilizer much to make tea water more green. This excessive chemical fertilizer application of tea farmers will have strong impact not only tea quality but also environment (through contaminating soil, air and water) and the life of plants and animals, including humans. Therefore, it is important to promote the implementation of integrated pest management (IPM) practices in order to reduce the dependence of tea farmers on chemical fertilizer. Similarly, the negative sign of Capital variable in some tea farms implies that there would be no significant increase in tea yield even if the investment in machinery increases. Some tea farmers have excess capital, which is either not used or not fully used in actual production. According to Pindyck (1990), when capital investment is often an irreversible decision, excess capital tends to persist. Therefore, these findings suggest that tea farmers have wide chance to increase tea yield through properly utilizing their current machineries.

The presence or absence of technical inefficiency effect was tested in the study using $z$ test. The null hypothesis is that there is no inefficiency effect in the model. The estimation result from Function (5) shows:

$$
z_{\text {statistic }}=\frac{\tilde{\lambda}}{\operatorname{se}(\tilde{\lambda})}=\frac{3.091}{0.014}=220.79
$$

$\mathrm{Z}_{\text {statistic }}$ exceed the $z$ critical value of 3.01 at the $0.1 \%$ level. Therefore, the null hypothesis was rejected, which indicated the presence of technical inefficiency effect for tea farmers in the Northern mountainous region of Vietnam.

Gamma $(\gamma)$ is equal to 0.901 , which means that $90.1 \%$ of the total variation of output levels is due to technical inefficiency.

We estimated output-oriented $T E$ and input-oriented $T E$ with the former calculated by using Equation (4) and the latter by Equation (11). The estimation results are summarized in Table 3.

The average output-oriented $T E$ was $92.29 \%$, with the variation from $69.67 \%$ to $98.85 \%$. This result suggests that the possibility of increasing current average output level, with given inputs is $7.71 \%$. None of farms have $T E$ score lower than $60 \%$, indicating that most of tea farmers in the study site achieve rather high output-oriented technical efficiency. Due to decreasing returns to scale, input-oriented $T E$ is expected to be lower than that of 
output-oriented TE. Respectively, the average input-oriented $T E$ score is $82.21 \%$, which is about $10.08 \%$ smaller than output-oriented TE. The tea farmers have the potential to reduce $17.79 \%$ observed levels of all inputs without compromising the current output level.

Table 3. Input and output-oriented technical efficiency scores by level

\begin{tabular}{|c|c|c|c|c|c|c|}
\hline \multirow{2}{*}{ TE levels } & \multicolumn{3}{|c|}{ Output orientation } & \multicolumn{3}{|c|}{ Input orientation } \\
\hline & Number & Percent & Cumulative percent & Number & Percent & Cumulative percent \\
\hline$\leq 60$ & 0 & 0.00 & 0.00 & 9 & 3.70 & 3.70 \\
\hline $60-70$ & 1 & 0.41 & 0.41 & 25 & 10.29 & 13.99 \\
\hline $70-80$ & 5 & 2.06 & 2.47 & 52 & 21.40 & 35.39 \\
\hline $80-90$ & 50 & 20.58 & 23.05 & 97 & 39.92 & 75.31 \\
\hline$\geq 90$ & 187 & 76.95 & 100.00 & 60 & 24.69 & 100.00 \\
\hline Mean & & 92.29 & & & 82.21 & \\
\hline Median & & 93.59 & & & 83.82 & \\
\hline Min & & 69.67 & & & 50.68 & \\
\hline Max & & 98.85 & & & 98.49 & \\
\hline
\end{tabular}

Source: Author's estimation.

Although tea production in the study site is facing with the over utilization of inputs, the farmers seem to focus more on increasing output level than contracting input use. The proof of this affirmation is that $99.59 \%$ of the farmers have output-oriented $T E$ above $70 \%$ while only $86.01 \%$ in case of the input-oriented TE. In fact, the tea yield in the Northern mountain region is the highest compared with other region (GSO, 2013). Under this context, input-orientation tea production technology which contract the utilization of inputs, especially environmentally detrimental inputs seems to be more appropriate in the region.

\subsection{Factors Affecting Resource Use Efficiency}

The Tobit model was applied to determine the factors affecting TE of tea production instead of the OLS estimate producing biased results, often toward to zero (Bravo-Ureta \& Pinheiro, 1997). As shown in the Equation (13), $T E$ was used as dependent variable and the socio-economic characteristics of the farmers were used as independent variables. 
Table 4. Marginal effects of determinants on resource use efficiency in Tobit model

\begin{tabular}{|c|c|c|c|}
\hline \multirow{2}{*}{ Variables } & \multirow{2}{*}{ Explanation } & \multirow{2}{*}{$\begin{array}{l}\text { TEo } \\
\text { Coef. }\end{array}$} & \multirow{2}{*}{$\frac{\text { TEi }}{\text { Coef. }}$} \\
\hline & & & \\
\hline Age & HH age (years) & -0.0003 & 0.0003 \\
\hline Gender & HH gender $(1=$ male, $0=$ female $)$ & $0.0382^{* * *}$ & 0.0201 \\
\hline Experience & $\mathrm{HH}$ experience in tea farming (years) & $0.0005^{* *}$ & 0.0009 \\
\hline Soil and water conservation & $1=$ farmer employed SWC technology, $0=$ otherwise & $0.0021^{* *}$ & $0.0149^{* * *}$ \\
\hline Farm value & Total value of agricultural product in natural logarithm & 0.0137 & $0.0673^{* * *}$ \\
\hline Extension & $1=$ farmer access to extension service, $0=$ otherwise & $0.0573^{* * *}$ & $0.0859^{* * *}$ \\
\hline Water scarcity perception & $\begin{array}{l}1=\text { farmer recognizes water scarcity in the study site } \\
0=\text { farmer does not recognize water scarcity }\end{array}$ & -0.0020 & $0.0289^{* *}$ \\
\hline Education & HH education level (years) & -0.0002 & -0.0020 \\
\hline Household size & Number of member per household & 0.0016 & 0.0021 \\
\hline Ethnicity & HH ethnicity $(1=$ Kinh, $0=$ otherwise $)$ & 0.0010 & 0.0010 \\
\hline Tea age & The age of tea tree in years & 0.0001 & 0.0004 \\
\hline Non-agricultural income share & Proportion of total income from non-agricultural sources & 0.0090 & -0.0003 \\
\hline Cooperative & $1=$ farmer join cooperative, $0=$ otherwise & -0.0144 & -0.0392 \\
\hline Farm size & $\mathrm{Ha}$ & -0.0137 & 0.0163 \\
\hline Well water & $1=$ well water, $0=$ otherwise & 0.0023 & -0.0064 \\
\hline Stream water & $1=$ stream water, $0=$ otherwise & 0.0013 & 0.0148 \\
\hline Constant & & $0.8158^{* *}$ & $0.3421^{* *}$ \\
\hline
\end{tabular}

Note. HH means house hold head, TEo and TEi indicate output-oriented TE and input-oriented TE, *** and ** indicate statistical significance of the 0.01 and 0.05 level.

Source: Author's estimation.

The sign of the variables in the Tobit model is very important in explaining the observed level of technical efficiency of the farmers. A positive sign on the coefficient implies that variables had an effect in increasing technical efficiency, while a negative coefficient signifies the effect of reducing technical efficiency.

Gender variable had positive effect to output-oriented technical efficiency. The positive sign of Gender variable shows that male head households have more ability to increase output than their female counterparts. This result is consistent with the findings of Due and Gladwin (1991) and Adesina and Djato (1997). Many factors explain the weakness of women's productivity. Women farmers often lack access to cash or credit to acquire modern yield-increasing inputs of production, they tend to produce less (Gladwin, 2002). The level of productivity of women is constraint because most agricultural technologies are designed based on the assumption that farm mangers are men (Balakrishnan, 2000). In reality, women farmers in the study site lack access to inputs, credit, and extension training because most of their time is spent doing housework like cooking, cleaning, washing, and caring children, apart from plucking and weeding possibly during the lean season. Most work in tea cultivation such as: buying inputs, fertilizing, pruning, spraying, managing fund, joining training courses is done by male farmers. Therefore, to improve women farmers' productivity in the region, women need to be better supported by increasing access to factors of production such as: land, credit, inputs, information and technology.

Experience variable also had positive effect to output-oriented technical efficiency. Farmers with much experience in tea farming can produce more output with given inputs as compared to those with less experience. This result is consistent with the finding of Basnayake et al. (2000).

The Soil and water conservation variable also had statistically positive effect on both types of efficiency. The effect is positive and significant at the $5 \%$ and $1 \%$ levels for output and input-oriented technical efficiency respectively. This indicates that famrers adopting of SWC technologies had more potential to expand output and to reduce inputs, compared with those who did not adopt these technologies. This result is consistent with Dang 
(2008), and Solis et al. (2006). In recent years, soil erosion resulting from bad farming practices on sloping lands, without attention to soil conservation, has been known to be a serious problem in the Northern mountainous areas of Vietnam. Soil erosion causes loss of productivity at all levels in this region (Thao, 2001). Therefore, the promotion of soil and water conservation practices is very important measure to produce tea efficiently and sustainably.

Farm value had significant positive impact on input-oriented technical efficiency. The positive sign of Farm value suggests that for farmers with higher agricultural income, their productive efficiency will be increased through reduction of inputs. With higher income, farmers can have more chance to improve knowledge of modern cultivation techniques or buy good machines, which lead to inputs saving in production process.

It is clearly shown from Table 4 that Extension variables had positive significant effects on both types of technical efficiency at the level of 1 percent, implying that accessing extension services can help tea farmers not only increase output but also save inputs use. Kalijaran (1991), Xu and Jeffrey (1998), Seidu (2008), Saigenji and Zeller (2009), and Nyagaka et al. (2010) also found that agricultural extension services could help improving technical efficiency. Agricultural extension policy was designed in Vietnam to develop agriculure production in a sustainable way. Tea production is one of the most important sectors implementing this policy. Extension service includes serveral features such as: training courses or technical instruction on tea cultivation (land preparation, planting etc.), training on modern techniques of application of fertilizer and pesticde, training on harvesting and conservation, provision of information on tea market and sale skills. Extension service is important tool in educating farmers and it could bring positive behavioral changes among farmers. Thus, it is essential for Vietnamese tea farmers to have easy access to extension services in order to optimize on-farm technical efficiency, given the limited resources available.

Water scarcity perception had significant positive impact on input-oriented technical efficiency. This implies that farmers recognize water scarcity in the study site will tend to improve production efficiency by reducing the use of inputs, specifically in irrigation water use. This finding is consistent with Tang et al. (2013). The finding has the important policy that changing behavior, such as improving irrigation water use efficiency should be stimulated through spreading information about water scarcity to farmers.

\section{Conclusions and Recommendations}

In this paper, we employed the translog stochastic frontier production function for cross-sectional data sets of 243 tea farms in 2014 to estimate resource use efficiency in the Northern mountainous region of Vietnam. We also characterized tea farmers in to social and economic classes and evaluate their impact on resource use efficiency. The results showed that these tea farms have an average output- oriented $T E$ level of $92.29 \%$, suggesting that farmers can still increase the current output level by $7.71 \%$, given fixed inputs. However, the mean sum of output elasticity with respect to specific inputs is 0.323 , indicating that those tea farms are decreasing return to scale. The average input-oriented $T E$ score is $82.21 \%$, which is much less than that of output-oriented $T E$, indicating that those tea farms in the study site could reduce the use of inputs by $17.79 \%$ without compromising the current output level. This analysis yielded an important finding that changes tea farmers' opinion. Conventionally, the farmers often think that the best way to improve productivity is to increase output by using inputs as much as possible. In fact, the tea farms in the Northern mountainous region of Vietnam should make an effort on reducing inputs, which will help the farmers not only save production cost but also improve the environmental quality. This direction will promote tea production in the Northern mountainous region of Vietnam sustainably.

The farmers' socio-economic and farm characteristics such as: applying soil and water conservation technology, accessing extension services, increasing agricultural income, and raising water scarcity recognition were found to be significant in increasing resource use efficiency of tea production in the region. To improve resource use efficiency, the government should encourage the practice of soil and water conservation technology, implement extension services widely, and promote farmers' awareness on water scarcity. The study also reveals that women tea farmers tend to produce less efficiently than their male counterparts. Policies which aim at increasing female farmers' access to production inputs as well as extension services will be useful for increasing output-oriented technical efficiency of tea production.

\section{Acknowledgements}

This research was funded by Setsutaro Kobayashi Memorial Fund in 2014. The authors thank Environmental Economics Laboratory, Faculty of Agriculture and Kyushu University for providing the opportunity and facilities to conduct the research. The authors are grateful to the unknown reviewers for their valuable suggestions and comments on this manuscript. 


\section{References}

Adesina, A. A., \& Djato, K. K. (1997). Relative efficiency of women as farm managers: Profit function analysis in Côte d'Ivoire. Agricultural economics, 16(1), 47-53. http://dx.doi.org/10.1016/S0169-5150(96)01212-1

Aigner, D., Lovell, C. A. K., \& Schmidt, P. (1977). Formulation and estimation of stochastic frontier production function models. Journal of Econometrics, 6(1), 21-37. http://dx.doi.org/10.1016/0304-4076(77)90052-5

Asian Development Bank. (2004). The value chain for tea in Vietnam: Prospects for participation of the Poor.

Balakrishnan, R. (2000). Widening gaps in technology development and technology transfer to support rural women. Human Resources in Agricultural and Rural Development, 80-91.

Basnayake, B. M. J. K., \& Gunaratne, L. H. P. (2000). Estimation of technical efficiency and it's determinants in the tea small holding sector in the Mid Country Wet Zone of Sri Lanka. Economics, 4(Part 1), 137-150.

Baten, A., Kamil, A. A., \& Haque, M. A. (2010). Productive efficiency of tea industry: A stochastic frontier approach. African journal of Biotechnology, 9(25), 3808-3816.

Battese, G. E., \& Corra, G. S. (1977). Estimation of a production frontier model: with application to the pastoral zone of Eastern Australia. Australian Journal of Agricultural Economics, 21(3), 169-179. http://dx.doi.org/10.1111/j.1467-8489.1977.tb00204.X

Belbase, K., \& Grabowski, R. (1985). Technical efficiency in Nepalese agriculture. The Journal of Developing Areas, 515-526.

Bravo-Ureta, B. E., \& Pinheiro, A. E. (1997). Technical, economic, and allocative efficiency in peasant farming: evidence from the Dominican Republic. The Developing Economies, 35(1), $48-67$. http://dx.doi.org/10.1111/j.1746-1049.1997.tb01186.x

Coelli, T. J., Rao, D. S. P., O’Donnell, C. J., \& Battese, G. E. (2005). An introduction to efficiency and productivity analysis. Springer Science \& Business Media.

Dang, M. V. (2008). Effects of tea cultivation on soil quality in the northern mountainous zone, Vietnam. Retrieved from http://hdl.handle.net/10388/etd-11032008-124714.

Do, N. Q., \& Le, T. K. (2000). Giao trinh cay che: San xuat, Che Bien, va Tieu Thu. Textbook of Tea Plantation: Field Management, Process and Marketing Product. Hanoi, Vietnam: Nha Xuat Ban Nong Nghiep.

Due, J. M., \& Gladwin, C. H. (1991). Impacts of structural adjustment programs on African women farmers and female-headed households. American Journal of Agricultural Economics, 73(5), 1431-1439. http://dx.doi.org/10.2307/1242398

Farrell, M. J. (1957). The measurement of productive efficiency. Journal of the Royal Statistical Society, Series $A$ (General), 253-290. http://dx.doi.org/10.2307/2343100

Gladwin, C. (2002). Gender and soil fertility in Africa: Introduction. African Studies Quarterly, 6(1/2).

GSO (General Statistic Office). (2011, 2013). Statistical year book of Vietnam.

Haridas, N., Kumar, S. A., Nerella, V. K., Deepika, M., \& Jyotishi, A. (2012). Measuring technical efficiency in tea plantations in India: A panel data analysis. Discussion paper.

Jondrow, J., Lovell, C. A. K., Materov, I. S., \& Schmidt, P. (1982). On the estimation of technical inefficiency in the stochastic frontier production function model. Journal of Econometrics, 19(2), 233-238. http://dx.doi.org/10.1016/0304-4076(82)90004-5

Kalirajan, K. P. (1991). The importance of efficient use in the adoption of technology: a micro panel data analysis. Journal of Productivity Analysis, 2(2), 113-126. http://dx.doi.org/10.1007/BF00156342

Kebede, T. A. (2001). Farm household technical efficiency: A stochastic frontier analysis. A Study of Rice Producers in Mardi Watershed In the Western Development Region of Nepal. Department of Economics and Social Sciences, Agricultural University of Norway. Retrieved from http://ub.uib.no/elpub/NORAD/2001/NLH/thesis01.pdf

Meeusen, W., \& Van den Broeck, J. (1977). Efficiency estimation from Cobb-Douglas production functions with composed error. International Economic Review, 435-444. http://dx.doi.org/10.2307/2525757

Nyagaka, D. O., Obare, G. A., Omiti, J. M., \& Nguyo, W. (2010). Technical efficiency in resource use: Evidence from smallholder Irish potato farmers in Nyandarua North District, Kenya. African Journal of Agricultural Research, 5(11), 1179-1186. 
Pindyck, R. S. (1990). Irreversibility, uncertainty, and investment. National Bureau of Economic Research. http://dx.doi.org/10.3386/w3307

Reinhard, S., Lovell, C. A. K., \& Thijssen, G. (1999). Econometric estimation of technical and environmental efficiency: an application to Dutch dairy farms. American Journal of Agricultural Economics, 81(1), 44-60. http://dx.doi.org/10.2307/1244449

Saigenji, Y., \& Zeller, M. (2009). Effect of contract farming on productivity and income of small holders: The case of tea production in north-western Vietnam. Retrieved January 10, 2012, from http://ageconsearch.umn.edu/bitstream/51681/2/669.pdf

Seidu, A. (2008). Technical efficiency of rice farmers in Northern Ghana. AERC Research paper, 178.

Shapiro, K. H., \& Müller, J. (1977). Sources of technical efficiency: The roles of modernization and information. Economic Development and Cultural Change, 293-310. http://dx.doi.org/10.1086/450948

Solis, D., Bravo-Ureta, B. E., \& Quiroga, R. E. (2006). The Effect of Soil Conservation on Technical Efficiency: Evidence From Central America. Paper presented at the 2006 Annual meeting, July 23-26, Long Beach, CA.

Tang, J., Folmer, H., \& Xue, J. (2013). Estimation of awareness and perception of water scarcity among farmers in the Guanzhong Plain, China, by means of a structural equation model. Journal of Environmental Management, 126, 55-62. http://dx.doi.org/10.1016/j.jenvman.2013.03.051

Thao, T. D. (2001). On-site costs and benefits of soil conservation in the mountainous regions of northern Vietnam. Economy and Environment Program for Southeast Asia (EEPSEA).

Van Der Wal, S. (2008). Sustainability issues in the tea sector: A comparative analysis of six leading producing countries. Stichting Onderzoek Multinationale Ondernemingen. Retrieved from http://papers.ssrn.com/sol3/papers.cfm?abstract_id=1660434

Vietnam Tea Association. (2012). General report on tea sector (p. 17).

Wenner, R. (2011). The Deep Roots of Vietnamese Tea: Culture, Production and Prospects for Development.

Xu, X., \& Jeffrey, S. R. (1998). Efficiency and technical progress in traditional and modern agriculture: evidence from rice production in China. Agricultural Economics, 18(2), 157-165. http://dx.doi.org/10.1016/S0169-5150(97)00050-9 


\section{Appendix}

Appendix A. OLS and MLE estimation of tea production frontier model

\begin{tabular}{|c|c|c|c|c|}
\hline \multirow{2}{*}{ Variables } & \multicolumn{2}{|c|}{ OLS } & \multicolumn{2}{|c|}{ MLE } \\
\hline & Coefficient & Std.error & Coefficient & Std.error \\
\hline Fertilizer & $7.354^{* * *}$ & 1.975 & $6.640^{* * *}$ & 1.685 \\
\hline Pesticide & -0.624 & 1.142 & -0.887 & 0.943 \\
\hline Labor & 1.516 & 1.001 & $1.960^{* *}$ & 0.830 \\
\hline Irrigation water & 0.551 & 0.869 & 0.533 & 0.678 \\
\hline Capital & -0.328 & 0.391 & -0.373 & 0.325 \\
\hline Fertilizer. Fertilizer & $-1.061^{* * *}$ & 0.284 & $-1.039^{* * *}$ & 0.231 \\
\hline Fertilizer. Pesticide & -0.056 & 0.159 & 0.028 & 0.136 \\
\hline Fertilizer. Labor & -0.081 & 0.104 & -0.112 & 0.085 \\
\hline Fertilizer. Irrigation water & 0.012 & 0.091 & 0.035 & 0.079 \\
\hline Fertilizer. Capital & $0.100^{* * *}$ & 0.048 & $0.122^{* * *}$ & 0.039 \\
\hline Pesticide. Pesticide & -0.054 & 0.201 & -0.022 & 0.188 \\
\hline Pesticide. Labor & 0.010 & 0.085 & 0.058 & 0.083 \\
\hline Pesticide. Irrigation water & 0.083 & 0.069 & 0.064 & 0.056 \\
\hline Pesticide. Capital & 0.031 & 0.036 & 0.015 & 0.031 \\
\hline Labor. Labor & -0.040 & 0.092 & -0.102 & 0.077 \\
\hline Labor. Irrigation water & $-0.138^{* *}$ & 0.056 & $-0.109^{* *}$ & 0.050 \\
\hline Labor. Capital & -0.013 & 0.027 & 0.002 & 0.022 \\
\hline Irrigation water. Irrigation water & 0.010 & 0.063 & -0.023 & 0.055 \\
\hline Irrigation water. Capital & -0.028 & 0.023 & -0.026 & 0.019 \\
\hline Capital. Capital & $-0.030^{* * *}$ & 0.013 & $-0.048^{* * *}$ & 0.011 \\
\hline Constant & $-20.778^{* *}$ & 9.126 & $-18.623^{* *}$ & 7.671 \\
\hline$R^{2}$ & 0.4268 & & & \\
\hline$\sigma_{v}$ & & & 0.034 & 0.006 \\
\hline$\sigma_{u}$ & & & 0.104 & 0.009 \\
\hline$\sigma^{2}$ & & & 0.012 & 0.002 \\
\hline$\lambda=\sigma_{u} / \sigma_{v}$ & & & 3.091 & 0.014 \\
\hline$\gamma=\sigma_{u}^{2} / \sigma^{2}$ & & & 0.901 & \\
\hline
\end{tabular}

Note. ${ }^{* *},{ }^{* * *}$ indicate statistical significance of the $0.05,0.01$ level.

Source: Author's estimation.

\section{Copyrights}

Copyright for this article is retained by the author(s), with first publication rights granted to the journal.

This is an open-access article distributed under the terms and conditions of the Creative Commons Attribution license (http://creativecommons.org/licenses/by/3.0/). 